\title{
The Effect of Low Temperature Plasma Nitriding on Wear Resistance of Ti6Al4V Alloy
}

\author{
O. Gul, N.Y. SARI And T. SinmazCElik \\ Kocaeli University, Mechanical Engineering Department, Umuttepe Campus, 41380 Izmit, Turkey
}

\begin{abstract}
The effect of low temperature plasma nitriding on wear resistance of Ti6Al4V alloy were investigated. There have been several studies to investigate the low temperature plasma nitriding on Ti6Al4V alloy. Plasma nitriding processes under gas mixture of $\mathrm{N}_{2} / \mathrm{H}_{2}=3$ were performed at temperature $535^{\circ} \mathrm{C}$ for duration of 4,8 and $12 \mathrm{~h}$. Adhesive wear tests were carried out by using a tribometer in block-on-ring configuration (ASTM G77), in sliding conditions, without lubricants and in air. Surface hardness of the plasma nitrided samples were measured by a Vickers hardness tester machine. Scanning electron microscopy studies were conducted to understand the wear mechanisms involved during the adhesive wear. Wear rate was calculated using weight loss per unit sliding distance. It was found that the wear resistance and surface hardness of the alloy improved considerably after plasma nitriding process. The wear resistance of the plasma nitrided samples were higher than of the unnitrided samples. Extension of nitriding times from $4 \mathrm{~h}$ to $12 \mathrm{~h}$ in the Ti6Al4V alloy improved remerkably the wear resistance and surface hardness.
\end{abstract}

DOI: $10.12693 /$ APhysPolA.125.491

PACS: 81.40.Pq, 81.65.-b

\section{Introduction}

Ti alloys are widely used in many areas such as aerospace, biomedical, military and automobile industry owing to their outstanding properties, which include light weight, excellent strength-to-weight ratio, easy fabrication, good biocompatibilty, low density, and high corrosion resistance. However, titanium alloys exhibit poor tribological properties including high and unstable friction coefficient and adhesive wear [1-4].

A series of surface modification processes, including physical vapor deposition, laser cladding, thermal oxidation and thermal spraying, chemical vapor deposition, plasma and laser nitriding, ion implantation have been proven to improve tribological property of titanium alloy. Nitriding of titanium and titanium alloys has been investigated for many years. Plasma nitriding is used to improve the surface hardness and sliding wear resistance of Ti6Al4V [5-9].

Plasma nitriding done at high temperatures (around $850^{\circ} \mathrm{C}$ ) degraded the plain fatigue properties of Ti6Al4V. Because of the grain growth during nitriding and the formation of compound layer possessing low fracture strength [10].

Low temperature nitriding improved not only the wear resistance and the corrosion resistance but also the fatigue strength of titanium [11].

In present study, adhesive wear of low temperature plasma nitriding of Ti6Al4V alloy were investigated. The treated samples were evaluated by means of microhardness and wear methods. The surface hardness, wear resistance and SEM images of wear tracks are considered in detail.

\section{Materials and methods}

Commercially Ti6Al4V alloy was used as the substrate for all plasma nitriding procedures. Cube-shaped samples with $11 \times 11 \times 11 \mathrm{~mm}^{3}$ in dimensions were prepared from square cross-section bars by a wire cutting machine. The specimens were grinded by $800,1000,1200,2000$, 2400 mesh emery papers, respectively. After cleaning with alcohol, the specimens were placed into the plasma nitriding chamber.

Plasma nitriding was done in an industry at a temperature of about $535^{\circ} \mathrm{C}$. A mixture of nitrogen and hydrogen in the ratio of 3:1 nitriding environment was used. Specimens were plasma nitrided for three different times $-4,8$, and $12 \mathrm{~h}$.

The dry sliding wear resistance of the nitrided samples were carried out by using a tribometer in block-on-ring configuration (ASTM G77), in sliding conditions, without lubricants and in air. The wear machine was stopped in every sliding distance of $100,200,400,700$, and $1000 \mathrm{~m}$ and the wear amount noted. AISI 52100 steel was used as ring material. The ring material was heated to $880^{\circ} \mathrm{C}$ and after standing $60 \mathrm{~min}$ the material was hardened to 62 HRC by quenching. The wear tests with a sliding distance of $1000 \mathrm{~m}$ were carried out at room temperature, a sliding speed of $160 \mathrm{rpm}$, normal loads of 6,12 , and $18 \mathrm{~N}$.

The surface hardness and microhardness profile were measured by using a Zwick Vickers hardness test machine at load of $100 \mathrm{~g}$ for the surface hardness and $10 \mathrm{~g}$ for the microhardness profile with a loading time of $15 \mathrm{~s}$. At the end of the $1000 \mathrm{~m}$ sliding distance, surface topography of each worn test sample was examined under JEOL/JSM-6060LV scanning electron microscope and photographs were taken of the worn surfaces of samples.

\section{Results and discussions}

Mass loss of unnitrided and plasma nitrided Ti6Al4V alloy versus the sliding distances at various loading rates are shown in Fig. 1. The wear resistance of the Ti6Al4V alloy considerably increased after applied plasma nitriding process. It can be seen in Fig. 1 that the nitriding 


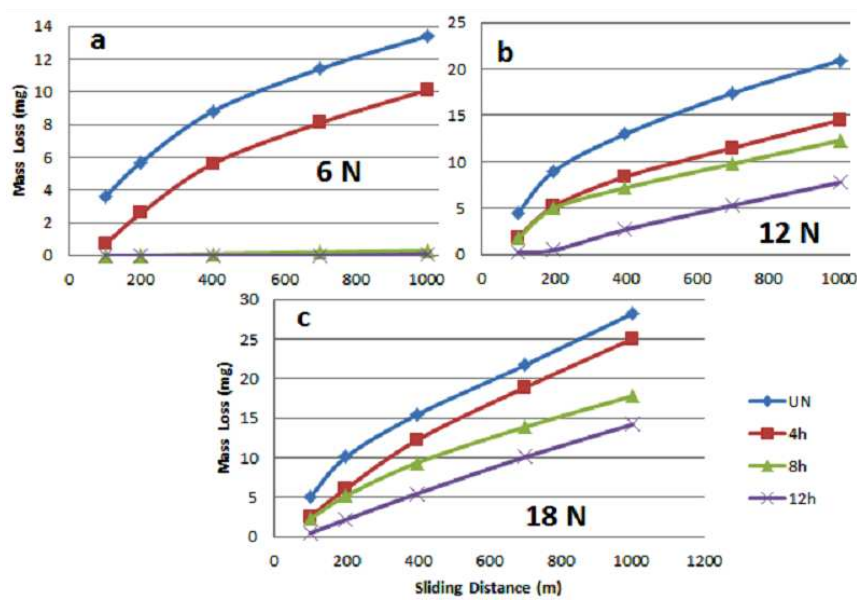

Fig. 1. Mass loss versus sliding distances: (a) $6 \mathrm{~N}$, (b) $12 \mathrm{~N}$, and (c) $18 \mathrm{~N}$.

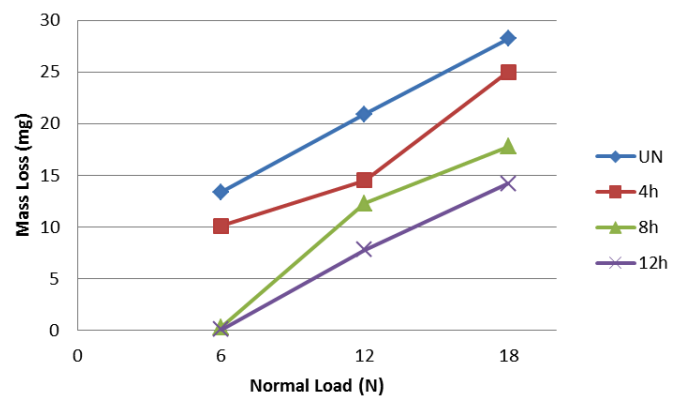

Fig. 2. Mass loss of Ti6Al4V alloy nitrided for various times as function of load.

time is an effective factor on the wear resistance of alloy. Figure 1 shows that the wear resistance of the nitrided alloy increases with increasing plasma nitriding time. It was noted that the highest mass loss values were obtained under $18 \mathrm{~N}$ load for all the samples. As seen in Fig. 1, wear amount increased with the increase of sliding distance. The mass loss results show that generally wear occurs more slowly under the load of $6 \mathrm{~N}$ than under the loads of 12 and $18 \mathrm{~N}$. Under a $12 \mathrm{~N}$ load, wear resistance of the Ti6Al4V alloy, nitrided $12 \mathrm{~h}$, increases about 3 times when compared with the unnitrided sample and 2 times higher than that of the sample nitrided for $4 \mathrm{~h}$ (Fig. 2).

The effect of nitriding temperature on the microhardness of Ti6Al4V is shown in Fig. 3. A significant increase up to $660 \mathrm{HV}_{0.01}$ in the surface hardness of plasma nitrided Ti6Al4V alloy was observed when compared with about $270 \mathrm{HV}_{0.1}$ in as-received material. The nitrogen atoms improve the hardness of the surface as a result of solid solution hardening in the diffusion layer because of causing enlargement of $\alpha$-Ti structure after the nitriding diffusion ability and depth of nitrogen atoms increase depending on the process time as expected for diffusion controlled growth [8]. The hardness values decrease from

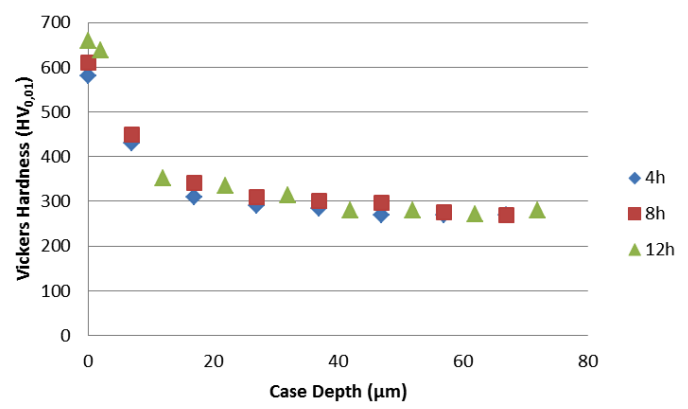

Fig. 3. Microhardness across the cross-section of the plasma nitrided samples.

the surface to core. The highest hardness was observed for $12 \mathrm{~h}$ plasma nitriding time.

Figure 4 shows SEM images of wear scars. The worn surface of the unnitrided Ti6Al4V alloy showed that alloy underwent high plastic deformation and adhesive wear. Unnitrided alloy shows very weak and unacceptable wear behaviour as it was expected. Samples nitrided for $4 \mathrm{~h}$ showed worse wear resistance than nitrided for $8 \mathrm{~h}$ and $12 \mathrm{~h}$. The depth and width of the wear tracks decreased with the increase in plasma nitriding time. On the contrary, the depth and width of the wear tracks increased with increasing normal load. The wear of $8 \mathrm{~h}$ and $12 \mathrm{~h}$ nitrided samples occurred in a very small amount at $6 \mathrm{~N}$ load. Consequently, increasing plasma nitriding time was a positive effect on improving wear resistance of Ti6Al4 V alloy.

For nitrided samples, initial stage of wear forming contained initiating microcracking in the wear track. Crack increasingly progressed as the sliding distance increased. The wear track exhibited plastic deformation, and deep grooves after removal of the compound layer. $18 \mathrm{~h}$ plasma nitrided samples exhibited shallow wear scars compared with other samples. The hard $\delta$-TiN structure produced on the surface after nitriding process decreased the amount of plastic deformation and caused lower wear amount. The wear mechanism for all nitrided samples occured as follows: step 1, matching and smoothing of the sliding surfaces; step 2, wear of the compound layer by adhesion and microfragmentation; step 3, wear of the diffusion layer by abrasion due to the third body formed by the hard nitride fragments [7].

\section{Conclusions}

The influence of nitriding low temperature and time as a function of normal load and sliding distance on the tribological behaviour of plasma nitrided Ti6Al4V alloy has been studied. Following conclusions can be drawn from results:

1. Plasma nitriding improved the sliding wear resistance of Ti6Al4V against AISI 52100 ring.

2. Applied plasma nitriding treatment increased the surface hardness of the Ti6Al4V alloy. 

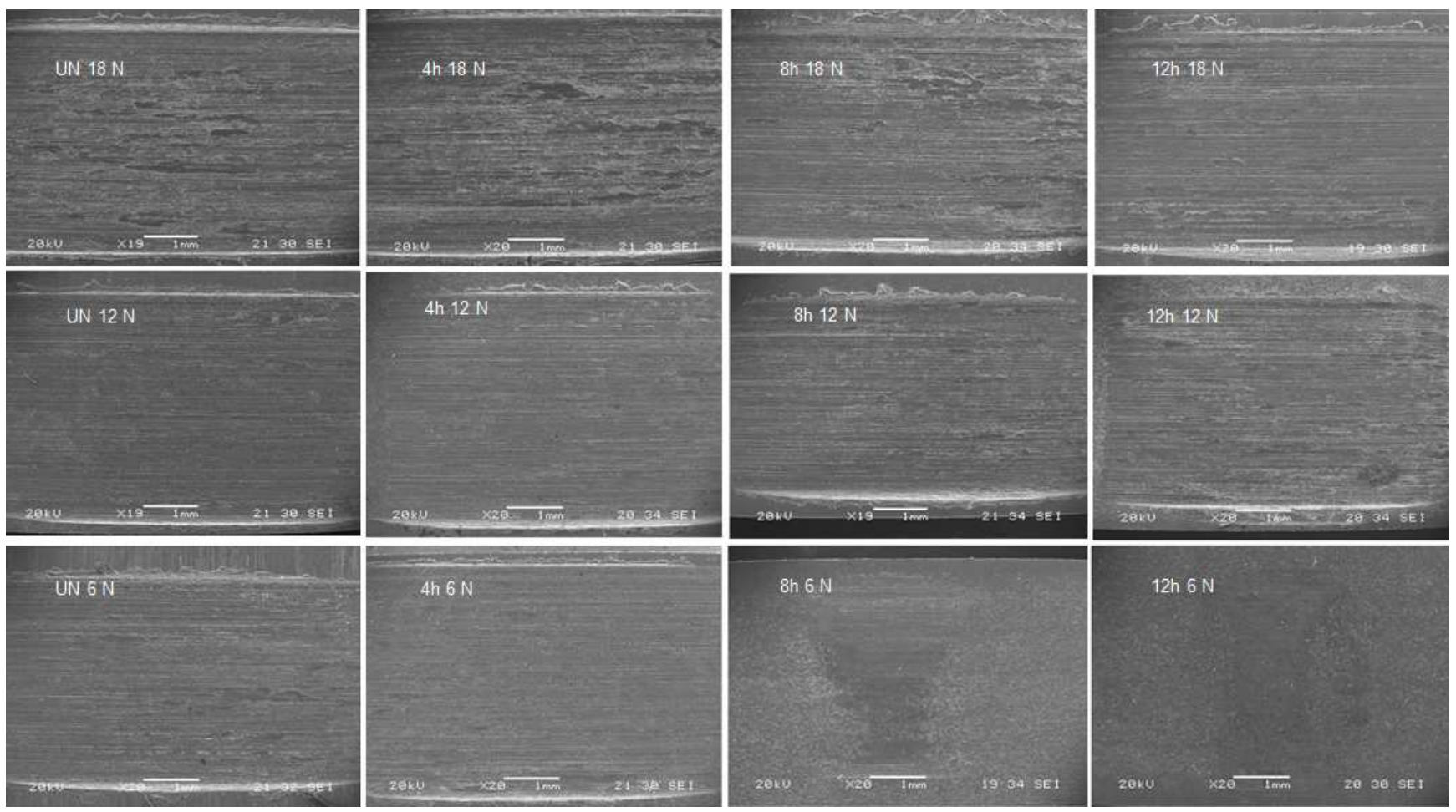

Fig. 4. SEM images of wear tracks for unnitrided (UN) and plasma nitrided Ti6Al4V samples under loads of 6,12 , and $18 \mathrm{~N}$ at sliding distance of $1000 \mathrm{~m}$.

3. Increasing plasma nitriding time improved tribological characteristics of the alloy significantly.

4. Plasma nitriding of Ti6Al4V alloy changes the sliding wear from adhesion to three body abrasion.

\section{References}

[1] A.F. Yetim, F. Yildiz, Y. Vangolu, A. Alsaran, A. Celik, Wear 267, 2179 (2009).

[2] G. Cassar, S. Banfield, J.C. Avelar-Batista Wilson, J. Housden, A. Matthews, A. Leyland, Surf. Coat. Technol. 206, 395 (2011).

[3] S. Farè, N. Lecis, M. Vedani, A. Silipigni, P. Favoino, Surf. Coat. Technol. 206, 2287 (2012).

[4] S.R. Hosseini, A. Ahmadi, Vacuum 87, 30 (2013).

[5] S. Maa, K. Xu, W.Q. Jie, Surf. Coat. Technol. 185, 205 (2004).
[6] D. Nolan, S.W. Huang, V. Leskovsek, S. Braun, Surf. Coat. Technol. 200, 5698 (2006).

[7] A. Molinari, G. Straffelini, B. Tesi, T. Bacci, G. Pradelli, Wear 203-204, 447 (1997).

[8] F. Yildiz, A.F. Yetim, A. Alsaran, A. Çelik, Surf. Coat. Technol. 202, 2471 (2008).

[9] B.S. Yllbas, A.Z. Sahin, A.Z. Al-Garni, S.A.M. Said, Z. Ahmed, B.J. Abdulaleem, M. Sami, Surf. Coat. Technol. 80, 287 (1996).

[10] M. Mubarak Ali, S. Ganesh Sundara Raman, S.D. Pathak, R. Gnanamoorthy, Tribol. Int. 43, 152 (2010).

[11] T. Morita, H. Takahashi, M. Shimizu, K. Kawasaki, Fatig. Fract. Eng. Mater. Struct. 20, 85 (1997). 